\title{
Stress and heart disease: evidence of associations between unemployment and heart disease from the OPCS Longitudinal Study
}

\author{
K.A. Moser, A.J. Fox, P.O. Goldblatt and D.R. Jones* \\ Social Statistics Research Unit, City University, London EC1, UK.
}

\begin{abstract}
Summary: The OPCS Longitudinal Study has been used to study both overall and cause-specific mortality patterns in 1971-1981 among men and women directly or indirectly affected by unemployment in April 1971. Groups studied included men seeking work in 1971, the wives of men seeking work in 1971 and other women in the same households as a man seeking work in 1971. The findings of this project are summarized here and attention is focused on mortality from circulatory diseases, in particular ischaemic heart disease. The study provides evidence which could be seen as supporting hypotheses about relationships between stress and overall mortality, with a marked excess for suicides. The evidence with respect to ischaemic heart disease is positive but less convincing with excess mortality from this cause principally occurring among younger unemployed men and among the wives of men who were seeking work in 1971. Given the sharp contrasts in the pattern and levels of unemployment between 1971 and 1981 it is difficult to extrapolate from these findings to the present day.
\end{abstract}

\section{Background}

The OPCS Longitudinal Study brings together census and vital registration records for approximately $1 \%$ of the population of England and Wales. The first major report (Fox \& Goldblatt, 1982) from this source looked at mortality in 1971-1975. It indicated raised all cause mortality for men seeking work in 1971 and aged 15-64 at death. These findings have been followed up in two more recent analyses (Moser et al., 1984; Moser et al., 1985) of mortality in the period 1971-1981 of these men. These two reports also provided information about the mortality of wives of men aged 15-64 and seeking work in 1971 and other women in households containing a man aged 15-64 and seeking work in 1971. In the present paper we summarize the findings of these analyses with respect to both all cause and suicide mortality and examine the evidence the study provides of any association between unemployment and ischaemic heart disease.

The methods we use are identical to those described in the earlier reports (although it should be noted that an error in the computer algorithm used in earlier analyses has led to minor discrepancies between the figures presented in earlier reports (Fox \& Goldblatt,

Correspondence: A.J. Fox. B.Sc., M.Sc., Ph.D.

*Present address: Clinical Epidemiology and Social Medicine, St George's Hospital Medical School, London SW17, UK.
1982; Moser et al., 1984) and those more recently published (Moser et al., 1986).

The initial sample of just over 500,000 people followed for the decade included nearly 6,000 men who were aged 15-64 and seeking work in 1971, nearly 3,000 women married to such men and nearly 5,000 other women in households containing such a man. A substantial fraction of this latter group will comprise daughters of men seeking work.

It is important to recognise that our concentration on men 'seeking work' means that we specifically excluded men who were out of work due to sickness. It should also be recognized that unemployment patterns and levels have changed considerably since 1971. In particular, cross-sectional surveys of the unemployed would today include much higher proportions of men who had been out of work for substantial periods of time (over a third have now been out of work for more than a year) and much lower proportions who were 'in-between jobs' (Smith, 1985).

\section{Results}

\section{Mortality from all causes and suicide}

Mortality in 1971-1981 of men seeking work in 1971 and aged 15-64 at death was higher than would have 
been expected from the death rates of all men in the OPCS Longitudinal Study in 1971. Some 347 deaths were observed in this group giving a standardized mortality ratio (SMR) of 137 with approximate $95 \%$ confidence interval (CI) (Vandenbroucke, 1982) of 123-152. The socio-economic distribution of the unemployed men in 1971 accounts for some of the excess mortality, but a $20-30 \%$ excess remains after allowance has been made for the housing tenure and social class distributions separately (Moser et al., 1984). A more recent analysis (Moser et al., 1986) has looked at the effect of standardizing for housing tenure and social class simultaneously and while suggesting some further reduction in SMRs, the excess still remains significant.

Mortality among unemployed men in the Longitudinal Study sample was found to be particularly high for young and middle-aged men with SMRs ranging from 150 to 200 for each 10-year age band between 15 and 54. Particularly high SMRs were noted for suicides, for which 20 deaths were observed, giving an SMR for men aged 15-64 of 236 (CI 144-365); for men aged 35-44 the SMR was 563 (CI 250-1000).

Further analysis shows that the excesses cannot be explained in terms of other socio-demographic characteristics of unemployed men, in particular their marital status composition or their geographic distribution. Indeed the all cause SMRs for men seeking work in the North and West was 141 (CI 118-167) relative to all men in the North and West, that for men in Central Regions was 143 (CI 116-173) relative to all men in Central Regions and that for men in the South and East was 118 (CI 96-143) relative to all men in the South and East.

All cause mortality for women whose husbands were 15-64 and seeking work in 1971 was also raised, but to a slightly lower degree than for men seeking work. Their SMR was 122 (CI 104-141) as compared with all women with a husband aged 15-64 in 1971 and resident in private households. Again, only a small fraction of the excess was accounted for by controlling for socio-economic characteristics such as economic position of the wife or housing tenure.

Although not statistically significant, we also found excess mortality for women in households containing a man (not her husband) aged 15-64 who was seeking work in 1971. For this group the SMR was 110 (CI 97-123). The all cause SMR in the age range 15-59 was nevertheless significantly raised (SMR of 154, CI 110-206).

For both these groups of women the SMRs for suicide were higher than the SMRs for other causes of death, but due to the small numbers of suicide deaths involved (four in the case of wives and three in the case of other women in the household), the SMRs of 160 and 143 respectively were not significantly raised (CI 40-360 and 26-355).

\section{Mortality from circulatory diseases}

Table I brings together the main findings on circulatory disease mortality among the three groups under study here.

For men aged 15-64 at death the SMRs for circulatory diseases as a whole and ischaemic heart disease in particular were raised but not significantly so; the SMRs were 117 (CI 98-138) and 113 (CI 92-138) respectively. However, a closer look at the data reveals particularly high mortality from these causes among younger men. Men aged 15-44 at death had an SMR for circulatory diseases of 186 (CI 114-287) and for ischaemic heart disease an SMR of 216 (CI 121-356). Although the equivalent results for men dying aged 45-64 show slightly raised SMRs, the confidence intervals are very wide.

The findings for wives of men seeking work in 1971 provide additional positive evidence in support of a hypothesis linking unemployment and heart disease. Table I shows SMRs of 134 (CI 105-166) for circulatory diseases and 152 (CI 111-200) for ischaemic heart disease. An examination of these data for narrower age bands does not indicate a result similar to that found for younger men. For women in households containing a man (not her husband) who was 15-64 and seeking work in 1971 the SMRs for these causes were slightly above 100 . Again there is no evidence of particularly high mortality from circulatory diseases or heart disease among more limited age ranges.

\section{Discussion}

The OPCS Longitudinal Study was originally established with a number of purposes in mind, although a study of the relationships between stress and heart disease was not foreseen at the outset (OPCS, 1973). Nevertheless, the paper by Jones (1985) and the present paper illustrate how the Longitudinal Study can be used to contribute information which will be of interest to researchers studying such relationships. Clearly, the main weaknesses of this source derive from the lack of any direct measurement of stress, either cross-sectionally or longitudinally. However, events such as the loss of a spouse or the loss of a job are considered to be stressful life events (Holmes \& Rahe, 1967) and the findings with regard to all causes mortality, and in particular mortality for suicides, strongly support expectations with respect to the effects of these events. Similarly, the high mortality from ischaemic heart disease among younger men is of interest and may provide further evidence of the adverse health effects of unemployment. There are suggestions, particularly for women married to men aged 15-64 and seeking work in 1971, that some excess 
Table I Mortality from circulatory diseases and ischaemic heart disease in 1971-1981 of persons affected directly or indirectly by unemployment in April 1971

\begin{tabular}{|c|c|c|c|}
\hline Group & $S M R^{*}$ & Deaths & $\begin{array}{c}\text { Approx } 95 \% \\
\text { confidence intervals }\end{array}$ \\
\hline \multicolumn{4}{|l|}{ Men seeking work in 1971} \\
\hline $\begin{array}{l}\text { Aged } 15-64 \text { at death } \\
\text { Circulatory diseases } \\
\text { Ischaemic heart disease }\end{array}$ & $\begin{array}{l}117 \\
113\end{array}$ & $\begin{array}{r}139 \\
99\end{array}$ & $\begin{array}{l}98-138 \\
92-138\end{array}$ \\
\hline $\begin{array}{l}\text { Aged } 15-44 \text { at death } \\
\text { Circulatory diseases } \\
\text { Ischaemic heart disease }\end{array}$ & $\begin{array}{l}186 \\
216\end{array}$ & $\begin{array}{l}20 \\
15\end{array}$ & $\begin{array}{l}114-287 \\
121-356\end{array}$ \\
\hline $\begin{array}{l}\text { Aged } 45-64 \text { at death } \\
\text { Circulatory diseases } \\
\text { Ischaemic heart disease }\end{array}$ & $\begin{array}{l}110 \\
104\end{array}$ & $\begin{array}{r}119 \\
84\end{array}$ & $\begin{array}{l}91-131 \\
83-129\end{array}$ \\
\hline \multicolumn{4}{|c|}{$\begin{array}{l}\text { Wives of men } 15-64 \text { and seeking } \\
\text { work in } 1971\end{array}$} \\
\hline $\begin{array}{l}\text { All ages at death } \\
\text { Circulatory diseases } \\
\text { Ischaemic heart disease }\end{array}$ & $\begin{array}{l}134 \\
152\end{array}$ & $\begin{array}{l}76 \\
47\end{array}$ & $\begin{array}{l}105-166 \\
111-200\end{array}$ \\
\hline \multicolumn{4}{|c|}{$\begin{array}{l}\text { Women in households containing a } \\
\text { man (not her husband) } 15-64 \text { and } \\
\text { seeking work in } 1971\end{array}$} \\
\hline $\begin{array}{l}\text { All ages at death } \\
\text { Circulatory diseases } \\
\text { Ischaemic heart disease }\end{array}$ & $\begin{array}{l}103 \\
101\end{array}$ & $\begin{array}{r}140 \\
58\end{array}$ & $\begin{array}{l}86-121 \\
77-130\end{array}$ \\
\hline
\end{tabular}

*Compared with all men or women in the LS in the same category but not restricted by economic position of the man.

mortality from ischaemic heart disease is to be seen.

The study is also limited by its inability to identify a group of men as they become unemployed but only a group who were already unemployed at a point in time, without knowledge of when they become unemployed. In consequence we are not able to look at relationships with duration of unemployment and our estimates of relative mortality are likely to be conservative. However, the analyses we now propose to undertake relating data from both the 1971 and 1981

\section{References}

FOX, A.J. \& GOLDBLATT, P.O. (1982). Socio-Demographic Mortality Differentials: OPCS Longitudinal Study 1971-75, Series LS no. 1, HMSO, London.

HOLMES, T.H. \& RAHE, R.H. (1967). The social readjustment rating scale. Journal of Psychosomatic Research., 11, 213.

JONES, D.R. (1985). Heart disease mortality following bereavement. SSRU Working Paper No. 36.

MOSER, K.A., FOX, A.J. \& JONES, D.R. (1984). Unemployment and mortality in the OPCS Longitudinal Study. Lancet, ii, 1324.

MOSER, K.A., FOX, A.J., JONES, D.R. \& GOLDBLATT, P.O. (1985). Further analyses of unemployment and mortality in the OPCS Longitudinal Study. SSRU Working Paper No 30.
Censuses to post-1981 Census mortality should provide interesting and important additional evidence.

\section{Acknowledgements}

These analyses form part of a review by members of the Social Statistics Research Unit at City University of mortality data available from the OPCS Longitudinal Study. (Crown copyright is reserved.) This programme is supported by a grant from the Medical Research Council. The views expressed are not necessarily those of the OPCS.

MOSER, K.A., FOX, A.J., JONES, D.R. \& GOLDBLATT, P.O. (1986). Unemployment and mortality: further evidence from the OPCS Longitudinal Study 1971-81. Lancet, i, 365.

OPCS (1973). Cohort Studies: New Developments. Studies in Medical and Population Subjects No 25. HMSO.

SMITH, R. (1985). Occupationless health. A doctor's guide to the facts and figures of unemployment. British Medical Journal, 291, 1107.

VANDENBROUCKE, J.P. (1982). A shortcut method for calculating the 95 per cent confidence interval of the standardised mortality ratio. American Journal of Epidemology, 115, 303. 